THE STEAM TURBINE IN LARGE MERCHANT STEAMERS.

W. MELVILLE,
gTATES NAVY.

Although I have aimed to be conservative in the following expression of my personal views on the use of the turbine in large merchant steamers, made at the re quest of the editor of the ScIENTIFIC AMERICAN, I have also sought to be something wore than general-to be concrete and specific enough to leave no question of my positive opinion. At the same time, I would wish to preface my comments with this statewent: That, gen erally, I realize the fact that the engineering world
wust go forward, and that by experiment, by trial and error, we must in part proceed; and, further, that it does not make for progress to throw too much cold water on the experimental and inventive stage of any form of machine, nor to dampen the ardor of the enthusiast, who, by attempting the impossible, often gains something not heretofore attained. On the other and one engineering fads and follies of the hour.

Furthermore, I heartily believe in every navy spending a proper amount of money in purely scientific experiment, to say nothing of practical experiments to a limited extent with certain more or less untried types
of vessels; and $I$ in no way wish, when commenting herein on the different governments that are installing the turbine in torpedo craft of their navies, to reflect on the policy of any naval power. For nations, to force the lead, have sometimes to take the experimental initiative themselves, even at great risk. Moreover, it ill becomes a progressive nation to sit
still and watch other nations experiment, and learn entirely from their failures, without bearing a part of the brunt of them itself.

Every engineer thoroughly appreciates that it is infinitely hard to predict the exact hour when the "tried and true" machine must give way to the actually better appliance. However, in making the following brief comments
I have been guided wholly by actually existing facts, and have tried to remember at all times the relation between theory, experiment and proved practice, as well as to bear in mind the vital prineiple of distinctiveness or individuality in mechanical appliances, which gives to certain forms of machines a mechanical advantage not to be secured in any other form, whose rejection for another would depend often upon certain conditions of service which give a special relative value to an advantage or disad vantage.

My opinion as the Engineer-in.Chief of the Navy may, or may not, be respected as ex cathedra in re gard to the steam turbine, as it may be in regard to any other mechanical device coming under the head of correct mechanical engineering. In the first place, it is the privilege, nay the right, of every scientist, physicist, or mechanical engineer to doubt the performance of any machine or contrivance until said apparatus has proved its correctness of design and utility, not only experimentally, but by useful perutility, not only experimentally, but by useful per-
formance of work for long periods of time. There are machine problems presented to the mechanical engineer every day that may appear mathematically and theoretically correct, but which will not stand the test

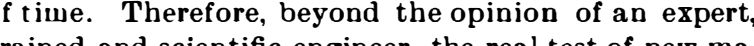
trained and scientific engineer, the real test of new macinines lies wholly in experiment and experience. I believe that the opinion of the expert, ninety-nine time out of a hundred, is correct, and is proved so when tested by actual experiment.

Now as regards the steam turbine, the question is Has it gotten beyond the experimental stage? There is not the slightest doubt that it will run, or that it has run to some purpose. But the question is, How well has it run, how economically has it run, or will it run; and to what extent may it take the place of the reciprocating steam engine? The whole engineering world knows how well the turbine, in respect of the speed attained, has performed in the "Turbinia" and in th "Viper;" but the question arises, Are not these merely racing machines? What value have these vessels beyond the fact that they have been propelled by the turbine at a very high rate of speed ? The engineering world demands something more in its vessels than mere speed. They must be useful for some specific mere speed. They must be useful for some specific
purpose, and the question may well be asked: Of what value is a vessel that has speed alone?

I do not believe that the turbine has yet prover itself efficient as a marine steam engine. It has done nothing that the reciprocating engine cannot do, and the reciprocating engine for marine purposes can do very readily many things that the turbine cannot so rery readily

I say this adviserly, in the face of the fact that Great Britain, France and Gerwany, and, I believe. Japan, have entered into contracts for experimental torpedo or other fast craft propelled by turbines. For thing more than a fast trial trip, to prove the utility of these craft. As regards its fitness for the werchant warine, turbine vessels should be put in service, and warine, turbine vessels should be put in service, and
continued in service as wage earners for weeks, months, and years, before we can express an intelligent opinion as to the probability of their supplanting vessels
gine.

Many of the high-speed torpedo boats of the nations of the world-I may say of all powers without exception-make high-speed trial trips, and are then laid up in reserve with a record for speed that is never again attained. In fact, many of them are tied up at navy yards or naval stations and permitted to rust out. In considering the practicability of the turbine for the merchant service, it is evident that no such record and results will be tolerated.

Heretofore, to realize any economy at all, the turbine has been compelled to run at very high velocities, unsuited to the present ideas of the marine screw propeller; and to get around this difficulty, many varying combinations of turbine and propeller have bee resorted to. But, were the turbine increased in size,
with a view to reducing its speed of revolution to with a view to reducing its speed of revolution to the hulls of our ships of to-day, I fear it would be inordinately large in diameter. Therefore, until turbines make a gradual growth from service in the high speed flier of to-day of little utility to that of the merchantman and the tramp, I do not believe any company would be justified in putting them in any great
liners.

On the other hand, because of its very high speed and reported economy, it seems particularly well suited for electric drive for dynamos, and Mr. George Westinghouse is about to put it to this test; and I doubt inghouse is about to put it to this test; and I d
not that it will turn out successfully in his hands.

The stationary engineering world will watch this ex periment with great interest. If the turbine in such service does not prove economical and durable, it will hasten its doom, for there is nothing that the turbine can do in this service that cannot be done equally well that the dynamos can be increased to any size to suit the piston speed of the reciprocating engine.

Therefore, in answer to your question, Mr. Editor, I am compelled to say that, for warine purposes. 1 do not believe that the turbine is to-day in a position to replace the reciprocating engine; and further, that unless it shows greater economy than it has heretofore shore.

The engineering world may be excused for expressing a conservative opinion on this matter, in view of the lack of those definite data as to coal, steam, and water consumption which as yet have not been made known to the public.

\section{National ACADEMY OF SCIENCES, PROVIDENCE MEETING.}

At the annual meeting, held in Providence, R. I., on November 13, the papers presented included two by Prof. T. W. Richards, in one of which he described a
porous cup voltometer which can measure the current absolutely with the satwe degree of accuracy with which you can measure electro-motive force. In the other he gave an account of the study of growing crystals by instantaneous microphotography. By ingeniously combining camera, microscope and electro-
motive force, he finds that the early stages of crystal formation are characterized by extremely rapid growth, so much so that distinct images can only be obtained by exposures of less than one-tenth of a second.

The papers of Dr. Charles S. Minot on development of the pig, the rabbit and the dogfish were further studies in progress of life and the action of vital forces from the embryonic to the senile stage in which he has so long labored, and with notable success in re gard to human life.

Prof. A. S. Packard, in his paper on the distribution and phylogeny of Limulus, showed that these land crabs occur in definite areas on the east coasts of both hemispheres; and their descent may be traced from
forms in the carboniferous. He also read'a paper on male preponderance (androrhopy) in lepidopterous in-

Prof. A. A. Michelson in two papers described improvements in the echelon spectroscope, and a very interesting analysis of the spectrum of sodium in a mag-
netic field, which could only have been made by this delicate instrument, because the lines are only $\frac{1}{3} 10$ of a 10th meter. The discovery by Zeeman that the lines of the spectrum of sodium are broadened when the sodium vapor is within the field of a magnet, he characterized as one of the most interesting of recent times. Michelson soon found that these lines were double; then Zeeman found them to be triple, and Michelson found that they separated farther as the density of the vapor increases; also a central line not previously present appears, which again dissodium vapor is very dense, it shows a double lin $€ 2$ ven when not in a magnetic field. The lines specially discussed were the characteristic sodium lines $D$ and $D_{2}$. It has been suggested that this is a double line ouly in appearance; the middle dark portion being an absorption band caused by interference. Prof. Michelson gave several reasons for rejecting this hypothesis, the most cogent of which seews to be that when an elliptical capillary $\frac{1}{10}$ millimeter by $1 / 2$ millimeter, with pressure of $\frac{1}{100}$ atmosphere, is used, the absorption is identical when the passage is through in either direction. These when the passage is through in either direction. These studies may throw light on the motions of
and their relations to the intersteilar ether.

Prof. Alpheus Hyatt, in two papers, gave a most elaborate presentation of his theory of progressive evolution of characters in the young stages of cephalopods, and a descriptive method of presenting the phenomena of pods ; so thoroughly worked out and graphically presented that Director Walcott, of the Geological Survey, remarked that he now for the first time really understood this theory, to which he had so of ten in previous meetings of the Academy heard Prof. Hyatt refer. Prof. S. L. Penfield, of Yale, read a paper on stereographic projection and some of its possibilities from a graphical standpoint. He found this the most practical method of pictorial representation of crystals ; and he considers it eminently useful for maps, being in fact the only system of projection whereby distances can be accurately and instantly measured upon the map. Even a schoolboy can readily use the protractor which Prof. Penfield has invented for this purpose. He illustrated this feature by using before the Academy a roughly graduated protractor, graduated only to five degrees; but even with this most of his measurements were accurate within a few minutes. Thus the diswithin three or four geographical miles, whereas maps within three or four geographical miles, whereas waps
which he had purchased, though much larger, showed errors ranging from six to nearly forty miles. By more finely graduated protractor, he can at once weasure all distances within

The principle is that of projecting a vertical arc on the diameter of a circle, as by drawing lines from all parts of the Northern Hemisphere to the South Pole, and using the plane drawn throngh the equator as a map. This system is, however, amenable to the objection that a protractor is indispensable in judging distances, beeause the center of the map is much crowded together, and it gradually expands in every direction till distances at the periphery are fully twice as great as at the center, hence the eye is quite misled. I this respect it distorts the inhabited portions of the earth even more than the Mercator projection, which is not seriously out of proportion except in circum. polar regions.

Director Charles D. Walcott, of the United States Geological Survey, has just brought back from eastern California some photograpbs of specimens showing in small compass good illustrations of the foldings and faultings of the Cordilleran area, which he exhibited and explained to the Acsdemy. The unethod of formation of these ranges, and the shapes assumed by them. are easily understood from these specimens, which consist of hard and brittle limestones alternating with softer strata, all folded together, and afterward subjected to stress and strain which has rent the hard strata in numerous places, producing faults close to gether, while the sof ter intervening strata have followed without cracking. In some instances the fault appears in two parallel hard strata, yet without affecting the atervening soft rock.

Prof. Carl Barus exhibited several ingenious pieces of apparatus invented by him. His demonstration of the projection of one grating upon another showed interesting optical effects. His wave machine, which has been already desç̧ibed in published articles, was exhibited for the first time. The variety of waves producible is marvelous: progressive, stationary, with stationary or with progressive nodes, reflected as from a dense to a rare medium, or vice versa, etc., illustrating sound, light polarization, elasticity, and much more. The recording system of two degrees of freedom in geniously combines two kinds of movements, that caused by the hairspring of a watch and that caused by gravitation. This is the first time that such a combination has been made ; and it was suggested that it might be appiied to practical use in àscertaining the ravitational effect of mountain chains, etc., in crossing a continent. The system consists of a watch suspended by its top, and having ballast below it, so that it swings as a pendulum, being capable of vibrations of large or small amplitude, and also of duration regu-
lated by the weight attached. The ffect is to make the watch run faster or slower than the normal rate, and many noteworthy results are produced.

The programme also mentioned the tube producing cloudy colored condensations, but as this requires a steam engine to actuate it. it was not shown. Many beautiful effects are produced, similar to sunset colors, and in some respects surpassing them.

After adjournment of the meeting, the members were invited to Ladd Observatory, where the tiny planet Eros was seen, being now in favorable position also the apparatus for observing the Leonid meteors was inspected. 